\title{
Socio-cultural Factors Influencing the Incidence of Tuberculosis in Abuja-Leather Mining Camp, Oyo State, Nigeria \\ DOI: 10.36108/NJSA/6102/14(0160)
}

\author{
Patricia. A. Taiwo \\ Adewale R. Adewuyi \\ Department of Sociology \\ Faculty of the Social Sciences \\ University of Ibadan \\ Ibadan
}

\begin{abstract}
Tuberculosis (TB) is a global pandemic with Nigeria ranked among countries with a high burden of the disease. While some countries have succeeded in halving the prevalence rate, the situation is not the same for Nigeria. This study utilized a semistructured questionnaire administered on 394 randomly selected respondents. Twelve In-depth Interviews (IDIs) and four Key Informant Interviews (KIIs) were conducted. Respondents' mean age was $35.0 \pm 10.4$ years. Over $90.0 \%$ had heard of TB, while over $60.0 \%$ identified cough that last longer than 3 weeks and coughing out blood as symptoms of TB. Respondents acquired their knowledge of TB from radio, health workers, family, friends and colleagues. While there was poor knowledge of other symptoms of TB, less than half of the respondents had knowledge of how TB could be cured and prevented. More than half of the respondents identified smokers and alcoholics as people that can be infected with TB. Regression analysis showed that only sex, level of education and ethnicity had significant independent prediction on the knowledge of how TB is contracted $\left(R=.329, R^{2}=.108, F=5.551, P<.05\right)$. More than half of the respondents had a belief that tuberculosis is a punishment from gods/goddess, a hereditary disease, and a spiritual attack from the enemies. Study showed that smoking, talking, coughing and sneezing while working in group in the mining pits especially with an infected person increase TB spread. The study recommends public health education and enlightenment programmes to reduce the spread of TB in relevant communities.
\end{abstract}

Keyword: Socio-cultural factors, TB knowledge, prevalence, infectious disease

\section{Introduction}

Tuberculosis (TB) is an infectious disease that is endemic in Nigeria (Dim and Dim, 2013). The World Health Organization (WHO) declared TB a global emergency in 1993, which till date has remained one of the world's major causes of illness and death. According to the report of the United States Embassy in Nigeria (2012), Nigeria ranks 10th among the 22 countries with high-burden of TB with Lagos, Kano, and Oyo states listed as having the highest prevalence rate. According to the report, other states have experienced a drop in identified cases resulting in a 4 percent overall decline of TB in 2010. 
Oyo state however, experienced an increase of identified TB cases by 46.5 percent from 2008 to 2010.

Tuberculosis is a serious but treatable infectious disease that affects different parts of the body, but most commonly the lungs or lymph nodes (Gerrish, Ismail and Naisby, 2010). It is caused by an acid-fast bacillus, which belongs to the Mycobacterium tuberculosis complex (Sagbakken, 2010). Its transmission commences with a human source, most often from a person with cavitary, pulmonary TB. It is often transmitted when an infected patient coughs, sneezes or talks, expelling the aerosols formed in the lungs. The expelled aerosols contain the micro-particles that carry the bacilli, which may in turn be inhaled by others (Sagbakken, 2010).

The common symptoms of TB include a persistent cough, fever often with night sweats, weight loss, and loss of appetite and tiredness (Gerrish et al. 2010). TB illness can take a different pattern, depending on which part of the body is affected. This is the reason why some infected people might, for instance, first complain of back pain (spinal TB), headaches or vision changes (TB of the brain). There is also non-respiratory TB which is more common in children, in immigrants from countries with a high prevalence rate, and in people with impaired immunity such as HIV infection or treatment with immunosuppressive agents (Comstock, 2000)]. The prevalence and urgent desire to control TB has made most people who are cured to have undergone a lengthy intake of antibiotics, while the disease has caused a permanent damage or death of others (Gerrish et al., 2010).

Despite the effort made by the Nigerian government and the International agencies to reduce the prevalence of TB in Nigeria and worldwide, there has been increase in TB spread in Oyo state (Dim and Dim, 2013). Most studies on TB focused on the bio-medical cure of tuberculosis infections (Mutinda, Kabiru. and Mwaniki, 2014), while little attention is paid to the socio-cultural factors influencing incidence of TB particularly among the people of Abuja leather mining camp of Oyo state. This paper therefore seeks to explore the socio-cultural factors influencing the incidence of TB by specifically seeking to assess the people's knowledge of Tuberculosis and identifying social factors influencing the prevalence of TB.

The knowledge of incidence and prevalence of TB varies among individuals. Some people have a high knowledge, some have a relatively low knowledge, while others have no knowledge about the disease. On the spread of information about tuberculosis, studies recorded that tuberculosis is treatable, preventable and controllable if the internationally recommended strategy for TB prevention, treatment and control are applied and adhered to (Mutinda, Kabiru and Mwaniki, 2014). Despite the widespread nature of tuberculosis, studies revealed scanty population-based information about symptoms of active tuberculosis (Loren, Steven, Emily, Laura, Lillian, and Davidson, 2000). Some other studies have also showed that tuberculosis is an 
infectious disease and its transmission is sustained where there are misconceptions and poor practices regarding its control (Mutinda et al., 2014).

According to Omotowo, Ekwueme and Aghaji (2012), speculations and beliefs about TB are closely tied to history and culture. Their study also noted that the prevalence of TB in African and Asian sub-regions was attributed to the initial poor knowledge of the disease through the course of history and lack of understanding which is also a current problem affecting the combat of the disease. Similarly, a study opined that such lack of understanding explains why men are usually unable to defend themselves against the terrible disease for long, leaving the people with only the option of illness and ultimate death (Jose, 2003). A study conducted in Benin-City of Nigeria showed that TB awareness programmes and knowledge of transmission of TB increased casedetection rates (Okuonghae, Omosigho, 2010). Studies also showed that Individuals who acknowledged the severity of TB are more likely to stay healthy (Colson, Franks, Sondengam, Hirsch-Moverman and El-Sadr, 2010). Hence, understanding the factors associated with the knowledge of and attitude towards tuberculosis is considered important and primary in promoting healthcare-seeking behaviour in Nigerian communities towards infectious diseases (Hoa, Thorson, Long, Diwan, 2003).

In a study conducted in Ethiopia on how to persuade patients to adhere to TB treatment, ignorance was identified as one of the causes of TB and its harmful effects on individuals and communities. It was also discussed as the most difficult factor that needs to be subdued for tuberculosis to be controlled (Demissie, Lindtjom, Berhane, 2002). Similarly, Omotowo et al., (2012) posited that lack of knowledge and poor understanding of the causes, signs and symptoms, transmission mechanisms and harmful effects of TB may not only delay initiation of treatment at both patient and hospital level, but may also cause poor adherence to treatment on the part of the patient and thus capable of truncating the effort or measures to control it. In line with this, Mutinda et al (2014) reported in a study conducted in Kenya, that despite the Directly Observed Treatment Short Course (DOTS) success in new case sputum smear and positive detection rates that has reached the WHO target of $70 \%$ and $72 \%$, respectively, and treatment success rate of $85 \%$ since the year 1997, TB transmission has remained a continues occurrence in Kenya.

Conversely, the findings of a study conducted by Oluwadere and Bosede (2010) among the people of Ekiti state in Nigeria showed that all the respondents were aware of the infection and symptoms of tuberculosis but very few, three men and one woman were aware of other TB infected person at the extended family level. On the perception of the dangers of TB, their study showed that 52 and 43 percent of male and female respectively believed that TB is "slightly dangerous" while 14 and 22 percent of male and female respondents believed it is dangerous and about 17 percent of all respondents believed that TB is not dangerous. In explaining what they know about TB, their study showed that appreciable level of knowledge of the infection made 
the respondents not to absolutely fear the epidemic in terms of not being curable or manageable.

The knowledge of contact tracing also contributed to peoples' knowledge about TB disease. In a study conducted by Awoyemi, Ige, Onadeko (2002), it was revealed that less than one-third of the TB patients studied had heard about contact tracing. It was discovered that the poor awareness of contact tracing among the TB patients contributed to the poor knowledge of the meaning of contact tracing reported by the patients. They further revealed that less than one-third of the patients with TB, knew that all the household members of sputum positive TB patients should have been present for screening. Their study however concluded that their findings may not provide adequate measures to TB transmission considering the fact that contact tracing is very necessary in establishing the primary source of TB and detecting all those who have secondarily infection was necessary for proper diagnosis and prompt treatment.

Furthermore, several factors influenced the prevalence of tuberculosis. Again, studies have shown that factors that have contributed to the increased rate of tuberculosis are the rise in the number of people who have suppression of the immune system, the development of drug-resistant strains of Mycobacterium, an aging population, and an increase in the number of healthcare workers who are exposed to the disease. The studies added that the human immunodeficiency virus (HIV) had remained the leading known risk factor for the reactivation of latent TB infection (Rieder, Cauthen, Comstock and Snider, 1989; Small, 1991; Reichman and Hershfield, 1993). Furthermore, some social factors that influence the prevalence of tuberculosis included cultural and human actions. For instance, Mutinda et al. (2014) posited that TB patients who are not on treatment have continued to transmit the infection to their close contacts, household associates, those in TB treatment facilities and those in the communities at large. They added that other factors known to sustain TB transmission in communities also included the duration taken before initiation of treatment, acceptance of TB status and reasons for seeking health care, TB status disclosure, and openness of one's TB status. Similarly, reports consistently showed that the prevalence of TB in environments was influenced by poverty, inadequate ventilation, overcrowding and malnutrition (WHO, 2010). This instigated the estimation that TB will rob the world poorest countries of an estimated 1-3 trillion US dollars over the next 10 years. As such, the reduction of TB incidence require improvement in socio-economic conditions that will lead to access to quality health care and rational use (WHO, 2010).

Effective policy implementation is another factor that influences the prevalence of TB in societies. The World bank report (2007) revealed that in the developed world, successful TB control programmes was achieved because of committed policies, public health and community strategic plans, 
demonstration areas and trained manpower inputs. Conversely, in less developed countries, such achievement remained uncertain. WHO (2009) report revealed that a general lack of infection control measures, outdated manuals and guidelines, inadequate labs, weak surveillance of drug resistant TB services, limited general access to TB services and inadequate human resources were common elements of less developed countries which influenced the prevalence of TB. This necessitated the WHO (2010) report which indicated that TB cannot be addressed without involving those mostly affected by the disease. The report further suggested that communities can help provide practical solutions to the problems faced by many who when ill from TB infection require diagnosis, proper care as well as professional health interventions. This further indicated that the prevalence of tuberculosis is influenced by individuals, health workers, community members and cultural practices.

\section{Theoretical/Conceptual Framework}

The theoretical framework adopted in this study is the determinant and explanatory model. The theory bothered on the explanatory ability of social status and other factors in determining the influence and outcome of phenomenon in terms of its prevalence and treatment. The Social Determinant Model of Health explains that health inequalities such as some experience of TB or lack of it, as well as access to good health care or lack of it influence the prevalence of TB, prevention and control of TB. The model explains that differences in health status between groups, population, or individuals exist because of unequal distribution of socio-cultural, environmental and economic conditions in societies, determining the risk of people getting ill, their ability to prevent sickness, or opportunities to have access to the right treatment. To this end, those who have adequate access to health care facilities are more likely to be able to prevent, treat and control the spread of TB, than those who do not. The same is likely for those who have high knowledge of the cause, symptoms and measures of preventing the disease which may be possible through access to information and contact with health workers which again may be a function of an individuals' socio-economic status.

Dahlgren and Whitehead (2010) identified the socioeconomic, cultural, environmental, living and working conditions, social and community influences, individual lifestyle, age, sex, educational level and hereditary factors as determinant of health in societies. In other words, this implies that the more favourable the circumstances, the more the chances of enjoying good health and a longer life (Equity Action Website). The cultural/behavioural explanation of Health Determinant Model emphasises that individuals' behavioural choices (e.g. tobacco and alcohol use, diet, physical activity, etc.) are responsible for the vulnerability of such persons to variety of diseases including TB. The model explains further that our health is determined in part by access to social and economic opportunities, the resources and supports available in our homes, neighbourhoods, and communities, the quality of our 
schooling; the safety of our workplaces, the cleanliness of our water, food, and air, and the nature of our social interactions and relationships (U.S Department of Health and Human Services 2014). The model reveals that the condition in which we live explains why some people have TB while others do not. As such, it explains the social factors influencing the prevalence of tuberculosis in a given area.

The explanatory model is often attributed to Arthur Kleinman (1976). The model explains peoples' knowledge of TB, how people make sense of their illness and their experiences of it, how people view their illness in terms of how it happens, what causes it, how it affects them, and what will make them feel better. Kleinman (1976) wrote that "eliciting the patient's (explanatory) model gives the physician knowledge of the beliefs the patient holds about his(/her) illness, the personal and social meanings he(/she) attaches to his//her) disorder, his(/her) expectations about what will happen to him(/her) and what the doctor will do, as well as his(/her) own therapeutic goals."

The explanatory model helps health researchers to understand their subjects. It helps to design appropriate therapies or interventions, and explains why some people reject medication or refuse to adhere to a prescribed TB therapy. The explanatory model is very relevant to this study because of its ability to integrate clinical, epidemiological and social science approaches (Weiss et al., 1992) thereby improving the depth of scientific understanding of TB. It also allows individuals to draw TB illness experiences and knowledge from participants in a structured way.

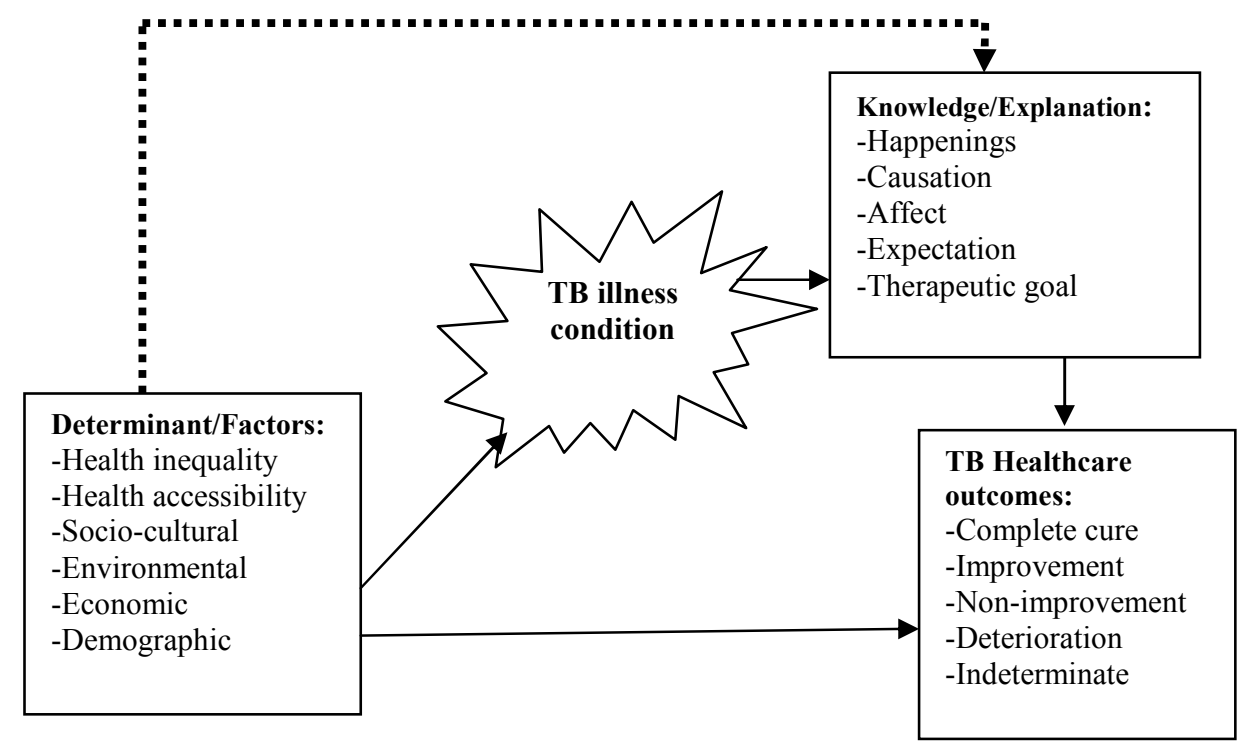

Figure 1: Conceptual Framework 
The above framework shows that TB illness condition, which is represented by explosive shaped structure, necessitates people's knowledge and explanations of the disease. Determinants such as health inequality, health accessibility, socio-cultural, environmental, economic and demographic factors influence people's knowledge of TB illness condition. The knowledge of an individual as well as the explanations s/he gives to the illness is based on the happenings, causation, affect, expectation and the therapeutic goals. The explanation adduced could influence TB health outcomes which can be in the form of cure, improvement, non-improvement, deterioration of the illness. Furthermore, the health outcomes as to whether there will be improvement or lack of it with reference to the disease condition, are also a function of the socio-cultural, economic, environmental and/or demographic factors.

\section{Methodology}

The study is a cross-sectional survey by design. It employed both quantitative and qualitative methods of data collection. The study was carried out among residents and workers of mining companies at Abuja leather mining camp of Oyo state, Nigeria due to the vulnerability of workers in this mining company to TB and the high prevalence rate of the disease in Oyo state which is yet to be reduced as compared to other high-burdened states in the federation. The simple random sampling technique was used select community members based on households' survey. The households selected are those within and around the community where the leather mining industry is located. A structured questionnaire was administered to workers and residents who are friends, relatives and colleagues of individuals in the industry both those that have been affected and treated from TB and those who have not. For easy sample selections, the table of random numbers was used to select households that fall within the list using numbers previously allocated to each of the households before selections. Purposive sampling technique was adopted to select participants for the qualitative methods. In-depth Interviews (IDIs) was conducted with TB patients and those who have been treated from the disease, while Key Informant Interviews (KIIs) was conducted with community health professionals and mining officials. This is considered appropriate because the study sought to ensure variation related to educational background, gender, cultural background and age in order to unfold hidden knowledge of the study matter from different categories of people with different perspectives.

The Statistical Package for Social Sciences was utilised in the entering, coding and analysis of data at the univariate, bivariate and multi variate levels. Descriptive statistics such as frequencies and percentages were employed to present demographic and background information of respondents consisting. Inferential statistics were employed to test multivariate variables. Qualitative data were elicited through IDIs and KIIs which were transcribed and content analyzed. To ensure the reliability of the study instruments, face validity and Nunnaly (1978) acceptable reliability coefficient of 0.7 and above was considd using SPSS Chronbach's alpha. Ethical principles guiding social sciences 
research such as informed consent, non-malfeasance to participants, anonymity and confidentiality were adhered to in the course of the study.

\section{Results}

\section{Socio-Demographic Characteristics of Respondents}

The socio-demographic characteristics of the respondents are presented in table 1 which showed that respondents' ages ranged from 18 to 70 years with a mean age of $35.0 \pm 10.4$ years. Majority of the respondents were aged below 40 years $(65.2 \%)$ which may be attributed to the nature of mining job done in the camp which requires the strength of able bodied persons. This also accounted for the reason why majority of the respondents $(78.1 \%)$ were males. More than half of the respondents $(59.4 \%)$ had below secondary education compared to $15.0 \%$ of them who had tertiary education. This implied that the study had more of less educated respondents. More than half of the respondents $(52.5 \%)$ were married, while $42.4 \%$ were single (never married).

On the respondents' major occupation, more than half $(53.0 \%)$ of the respondents were into mining while $19.3 \%$ were into business/trading. This is particularly so, because of the study area which was located in mining camp. About $35.0 \%$ of the respondents were Hausa, while $30.2 \%$ were Yoruba. About, $41.7 \%$ earned less than the country's minimum wage of N18,000 per month, while $78.9 \%$ of the respondents lived on or below N40,000 in a month. More than half (52.3\%) practiced Christianity while $45.7 \%$ were Muslims. This may also be because the study was conducted in the South west, Nigeria where Christian and Islamic religion existed.

Table 1: Socio-Demographic Characteristics of Respondents

\begin{tabular}{|l|c|c||}
\hline \hline Characteristics & Frequency $(\mathbf{N}=\mathbf{3 9 4})$ & Percentage \\
\hline Age (years) & & \\
\hline $18-24$ & 72 & 18.3 \\
\hline $25-29$ & 49 & 12.4 \\
\hline $30-34$ & 75 & 19.0 \\
\hline $35-39$ & 61 & 15.5 \\
\hline $40-49$ & 69 & 17.5 \\
\hline 50 and above & 68 & 17.3 \\
\hline Sex & & \\
\hline Male & 307 & 78.1 \\
\hline Female & 87 & 21.9 \\
\hline Level of Education & & \\
\hline No formal education & 140 & 35.5 \\
\hline Primary & 94 & 23.9 \\
\hline Secondary & 101 & 25.6 \\
\hline \hline
\end{tabular}


The Nigerian Journal of Sociology and Anthropology Vol. 14 no. 1

\begin{tabular}{|l|c|c||}
\hline \hline Tertiary & 59 & 15.0 \\
\hline Marital Status & & \\
\hline Single & 167 & 42.4 \\
\hline Married & 207 & 52.5 \\
\hline Divorced/Separated & 12 & 3.0 \\
\hline Widowed & 8 & 2.0 \\
\hline Major Occupation & & \\
\hline Civil/Public Service & 12 & 3.0 \\
\hline Farming/Fishing & 49 & 12.4 \\
\hline Mining & 209 & 53.0 \\
\hline Business/Trading & 76 & 19.3 \\
\hline Student & 48 & 12.2 \\
\hline Ethnic Group & & \\
\hline Hausa & 139 & 35.3 \\
\hline Yoruba & 119 & 30.2 \\
\hline Igbo & 51 & 12.9 \\
\hline Others & 85 & 21.6 \\
\hline Monthly Income & & \\
\hline Below N18,000 & 164 & 41.7 \\
\hline N18,000-N40,000 & 146 & 37.2 \\
\hline N40,001-N62,001 & 46 & 11.7 \\
\hline N62,002 and above & 37 & 9.4 \\
\hline Religion & & \\
\hline Christianity & 206 & 52.3 \\
\hline Islamic & 180 & 2.0 \\
\hline Traditional & 8 & \\
\hline \hline
\end{tabular}

Note: Mean age $=35.0 ;$ standard deviation $=10.4$

\section{Respondents' Knowledge of Tuberculosis}

Figure 1 shows the distribution of respondents by knowledge of ever heard of tuberculosis disease. 
Figure 1: Distribution of Respondents by Ever Heard of Tuberculosis Disease

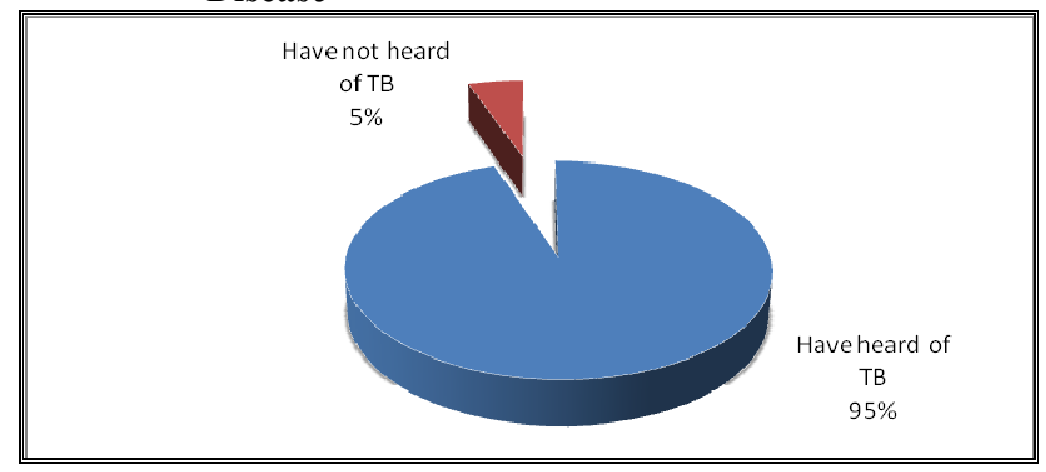

The results showed that almost all the respondents (95\%) have heard of the disease called tuberculosis, compared to $5.2 \%$ who had not. This implied that tuberculosis as a disease is not strange to the respondents. This finding is consistent with a recent study conducted in Nigeria which showed that the proportion of individuals who had ever heard of an illness called TB was $74.7 \%$ (Agbo et al., 2014)

Figure 2: Distributions of Respondents by their Source of Knowledge of TB

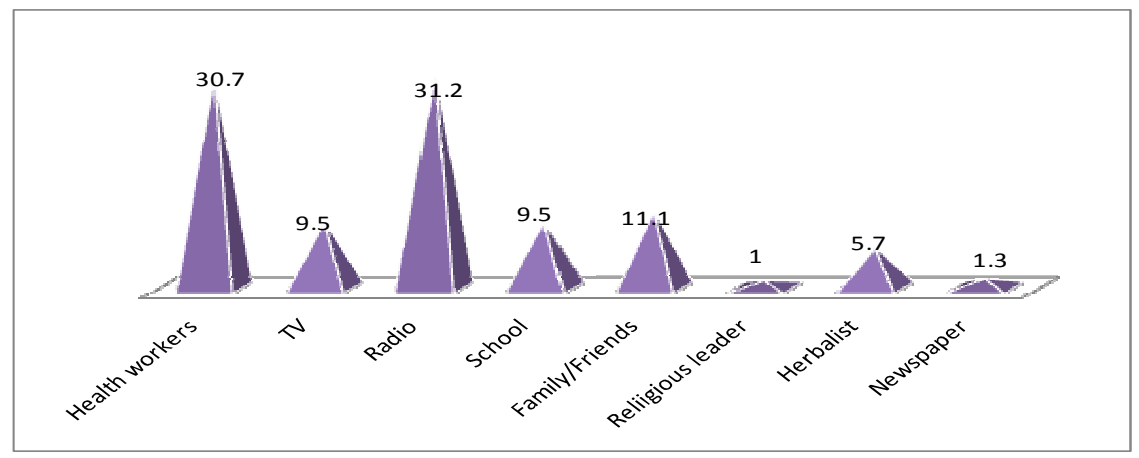

Figure 2 above presents respondents' sources of knowledge of tuberculosis. The results showed that most of the respondents acquired their knowledge of tuberculosis mainly from radio, health workers, and family, friends and colleagues $(31.2 \%, 30.7 \%$, and $11.1 \%$ respectively). This also implies that both formal and informal sources of information influence respondents' knowledge of tuberculosis.

An IDI conducted with an Ex-TB patient, whose occupation is mining revealed that he acquired his knowledge of tuberculosis from radio. He also 
identified some symptoms of tuberculosis to include cough and weight loss. He presented it using these words:

What I know about tuberculosis is; it is an infectious disease that is dangerous to our body. It affects the immune system of one's body. It makes someone to lose weight and usually cough, and also expel sputum from the lungs... I first heard of TB disease from radio. ...when I noticed the symptoms in me, I quickly went to the hospital for tuberculosis screening test.

(IDI/42years/Male/Ex-TB patient/2015)

In an IDI conducted with another community member. The interviewee also revealed that she first acquired her knowledge of tuberculosis from radio. In her words:

Tuberculosis is one of the serious diseases often announced then over the radio that it can be cured. ...I first learned about TB from radio. (IDI/22years/Female/Community member/2015)

Another interwiewee who was also a miner narrated that he learnt about tuberculosis from his neighbour who was in a time infected by tuberculosis. He presented it using these words:

It is said that TB is a particular cough that affect human body system. It is a contagious disease that can be easily contracted if ones family member is infected. And, if someone continues to sleep in the same room or share plate of food or spoon with him (referring to TB patients) such a person can also get TB. ...I was able to know about tuberculosis from my neighbour who was a TB patient. (IDI/ 38years/Male/Community member/2015)

Table 2 presents the respondents multiple responses on knowledge of symptoms of tuberculosis. The table showed that majority of the respondents identified cough that last longer than 3 weeks $(71.1 \%)$ and coughing out blood $(61.1 \%)$ as symptoms of tuberculosis disease. The table further showed that most of the respondents were not aware that weight loss, excess night sweating, fever that last longer than 7 days without clear cause and pain in the chest are also symptoms of tuberculosis. This implies that the respondents had partial knowledge of the symptoms of tuberculosis disease.

Table 2: Respondents' Knowledge of TB (N=394)

\begin{tabular}{|l|c|}
\hline \hline Knowledge of Symptoms & \% of Cases \\
\hline Cough that last longer than 3 weeks & 71.1 \\
\hline Coughing out blood & 61.1 \\
\hline Weight loss without knowing cause & 15.7 \\
\hline Night sweating & 22.7 \\
\hline Fever that last longer than 7 days without clear cause & 17.8 \\
\hline Pain in the chest & 13.7 \\
\hline \hline
\end{tabular}




\begin{tabular}{|l|c|}
\hline \hline Knowledge of how TB can be cured & \\
\hline Specific drugs from medical/health centre & 41.0 \\
\hline Direct Observe Short (DOTS) & 10.3 \\
\hline Prayer & 22.2 \\
\hline Resting without taking drugs & 36.8 \\
\hline Eating nutritious food without drugs & 17.8 \\
\hline
\end{tabular}

Table 2 showed that a higher percentage of the respondents identified taken specific drugs from medical/health centre (41.0\%), resting without taking drugs $(36.8 \%)$ and prayer $(22.2 \%)$ as ways of curing disease. Their choice of options showed that only $10.3 \%$ of the respondents correctly identified Direct Observed Short (DOTS) as a means of curing TB disease, although about $41.0 \%$ of them had identified taken specific drugs from medical/health centre as a way of curing disease which is also correct.

Table 3: Shows multiple responses by respondents' knowledge of how tuberculosis is prevented

\begin{tabular}{|l|c|}
\hline Responses & \% of Cases \\
\hline Not offending gods/goddess & 2.5 \\
\hline Being prayerful & 22.0 \\
\hline Eating good food & 11.5 \\
\hline Avoiding where there is crowd & 14.6 \\
\hline Covering nose \& month when sneezing/coughing & 25.8 \\
\hline Immunising TB Vaccine & 43.4 \\
\hline
\end{tabular}

Table 3 above shows that $25.8 \%$ of respondent identified that tuberculosis could be prevented by covering nose and mouth when sneezing or coughing, while $43.4 \%$ mentioned immunising with TB vaccine. Others identified not offending the gods/goddess, prayer, eating good food, and avoiding crowd as major means of preventing TB infection. This implies that less than half of the respondents had a good knowledge of how tuberculosis can be prevented. An interview conducted revealed that people who adhere to traditional herbs and roots as cure to tuberculosis have a belief that tuberculosis is a disease that accompanies hard and menial labour. He presented by saying:

Most of us in this community, including myself believed that tuberculosis is an illness that usually accompany hard menial labour, and can be managed by traditional herbs and roots. That is why we always take different concoction made of herbs and roots to cure illnesses. (IDI/42years/Male/Community member/ 2015) 
Another IDI response showed that the community members often used tradition and religious methods to prevent and cure the disease before seeking medical care services. She expressed thus:

Most of those sick of TB in this community that I have seen did use different traditional and religious means of curing TB disease. It is only when these have failed that they are taken to hospital to receive treatment. One person I know spent close to a year in the town receiving treatment... Yes, he went their very sick and slim but has return home healthy. (IDI/46years/Female/Community member)

Table 4 presented multiple regression analysis showing the influence of respondents' background characteristics (socioeconomic and demographic) on the knowledge of how tuberculosis is contracted. The results showed that age, sex, level of education, marital status, occupation, cultural background, religion and income jointly predicted the knowledge of how TB is contracted among residents of Abuja leather mining camp $\left(\mathrm{R}=.329, \mathrm{R}^{2}=.108, \mathrm{~F}=5.551\right.$, $\mathrm{P}<.05)$.

Table 4: Multiple Regression Analysis Showing the Influence of Respondents' Background Characteristics on the Knowledge of How TB is contracted

\begin{tabular}{|l|c|c|c|}
\hline \hline Variable & B & T & Sig \\
\hline Age & -.120 & -1.899 & .058 \\
\hline Sex & -.148 & -2.645 & $.009^{*}$ \\
\hline Level of education & .142 & 2.716 & $.007^{*}$ \\
\hline Marital status & -.066 & -1.078 & .282 \\
\hline Occupation & .019 & .347 & .729 \\
\hline Cultural background & .251 & 4.006 & $.000^{* *}$ \\
\hline Religion & .076 & 1.223 & .222 \\
\hline Income & -.043 & -.800 & .424 \\
\hline \hline
\end{tabular}

Sig level: $*<0.05 ; * *<0.005$

This implies that age, sex, level of education, marital status, occupation, cultural background, religion and income jointly accounted for about $10.8 \%$ variance in knowledge of how $\mathrm{TB}$ is contracted by the people of the community. However, only sex, level of education and cultural background had significant independent prediction on the knowledge of how TB is contracted.

\section{Social Factors Influencing the Prevalence of TB}

Table 5 presents multiple responses by respondents' on issues related to sociocultural factors influencing the prevalence of tuberculosis in the study area. The table showed that the people had some socio-cultural beliefs and practices that in turn affected the spread of the TB in the study area. Results also 
revealed that most of the respondents believed that tuberculosis is a punishment from the gods/goddess (28.5\%), tuberculosis is hereditary $(18.8 \%)$; that is they believed that if their parents did not have TB at the period of their birth, they will no more be infected by tuberculosis, $18.5 \%$ believed that the disease is a spiritual attack from enemies to their victims, about $18.2 \%$ believed that health workers may infect anyone who visit the hospital with TB, and $15.7 \%$ believed that TB cannot be cured in the hospital/health centre. All these factors at one point and the other influence the increase in prevalence of TB in the study area. This finding is consistent with the study which reported that tuberculosis is traditionally known by the people and it is conceived as a very contagious disease with high mortality rate (Oluwadare and Oluwasanmi, 2003).

Table 5: Socio-cultural Factors Influencing the Prevalence of TB

\begin{tabular}{|l|c|}
\hline \hline Responses & \% of Cases \\
\hline TB is a punishment from gods/goddess & 28.5 \\
\hline TB cannot be cured be cured in hospital/health centre & 15.7 \\
\hline TB can only be cured by traditional means & 3.8 \\
\hline Better to die of sickness than seek medical care & 7.8 \\
\hline Health workers may infect one with TB in hospital & 18.2 \\
\hline Hospital meant for only the educated class & 14.1 \\
\hline Hospital is meant for only the rich & 3.8 \\
\hline TB is Hereditary & 18.8 \\
\hline TB is a spiritual attack & 18.5 \\
\hline TB infected person will lack married partner & 15.0 \\
\hline
\end{tabular}

Table 6 presents a cross-tabulation table of percentage of socio-cultural factors by knowledge of who can be infected with tuberculosis disease. The result showed that socio-cultural factors influence the respondents' knowledge of symptoms of tuberculosis. Majority of those who are influenced by the sociocultural factors identified smokers as those who can be infected with tuberculosis. This was followed by those respondents who had a belief that it is those who offended the gods/goddess that can be infected with tuberculosis. Only a very few of the respondents were aware that anybody who is exposed to a TB infected person without a preventive measure can be infected with the disease. These findings corroborate with a study which showed that respondents lack adequate knowledge about the cause, transmission, and significant symptoms of diseases such as TB (Lienhardt, 2001; 2005; Koay, 2004). The findings also corroborate with an earlier study conducted in Nigeria which showed that knowledge of the aetiologic agent and route of transmission of tuberculosis disease are poor among the people (Omotowo et al., 2012). 
Table 6: Percentage of Socio-cultural Factors by Knowledge of Who Can Be Infected with Tuberculosis Disease

\begin{tabular}{|l|c|c|c|c|c|c||}
\hline \hline & \multicolumn{5}{|c|}{ Who Can be Infected With TB } & \\
\cline { 2 - 6 } $\begin{array}{l}\text { Socio-cultural } \\
\text { Factors }\end{array}$ & $\begin{array}{c}\text { Gods/ } \\
\text { goddess } \\
\text { offenders }\end{array}$ & $\begin{array}{c}\text { Precious } \\
\text { stone } \\
\text { dealers }\end{array}$ & Smokers & $\begin{array}{c}\text { AIDS } \\
\text { patients }\end{array}$ & $\begin{array}{c}\text { Poor } \\
\text { people }\end{array}$ & Anybody \\
\hline $\begin{array}{l}\text { TB is a punishment } \\
\text { from the gods/goddess }\end{array}$ & 22.0 & 4.4 & 69.2 & 0.0 & 0.0 & 4.4 \\
\hline $\begin{array}{l}\text { TB cannot be cured in } \\
\text { the hospital/health } \\
\text { centre }\end{array}$ & 16.0 & 14.0 & 36.0 & 16.0 & 18.0 & 0.0 \\
\hline $\begin{array}{l}\text { TB can only be cured } \\
\text { by traditional means }\end{array}$ & 33.3 & 0.0 & 66.7 & 0.0 & 0.0 & 0.0 \\
\hline $\begin{array}{l}\text { Better to die of } \\
\text { sickness than seek } \\
\text { medical care }\end{array}$ & 32.0 & 32.0 & 36.0 & 0.0 & 0.0 & 0.0 \\
\hline $\begin{array}{l}\text { Health workers may } \\
\text { infect one with TB in } \\
\text { the hospital }\end{array}$ & 13.8 & 0.0 & 65.5 & 6.9 & 6.9 & 6.9 \\
\hline $\begin{array}{l}\text { Hospital is meant for } \\
\text { only the educated class }\end{array}$ & 8.9 & 0.0 & 91.1 & 0.0 & 0.0 & 0.0 \\
\hline $\begin{array}{l}\text { Hospital is meant for } \\
\text { the rich }\end{array}$ & 33.3 & 0.0 & 66.7 & 0.0 & 0.0 & 0.0 \\
\hline TB is hereditary & 20.0 & 8.3 & 45.0 & 6.7 & 6.7 & 13.3 \\
\hline $\begin{array}{l}\text { TB is a spiritual attack } \\
\text { from enemies }\end{array}$ & 0.0 & 6.8 & 86.4 & 0.0 & 0.0 & 6.8 \\
\hline $\begin{array}{l}\text { TB infected persons } \\
\text { lack married partners }\end{array}$ & 8.3 & 0.0 & 0.0 & 50.0 & 25.0 & 16.7 \\
\hline \hline
\end{tabular}

An IDI conducted with an Ex-TB patient revealed that miners smoke cigarettes and drink alcohol. The interviewee who was an Ex-TB patient believed to have been infected with the disease by one of the miners while working and sharing things together in the mining camp. In his words:

I believed I got the disease (referring to TB) from the common habit of exchanging a stick of cigarette with my fellow colleagues in my place of work. ...In the mining camp, smokers and alcoholics are common because of the nature of the job. Some people even take some other illicit drugs to enable them work well. ...we often share things in common.

(IDI/38years/Male/Ex-TB patients/2015)

An interview conducted with another respondent revealed that a common practice of expelling sputum without covering the mouth or coughing while others are eating without covering mouth influences the spread of the disease in the area. The interviewee put it this way:

...cultural practice that can influence the prevalence of tuberculosis in this community is the habit of expelling sputum without covering it. Sometimes some people will see others 
eating food, but still cough and expel it. This is peculiar to majority of the Hausa's in this community... (IDI/22years/Female/Community member/2015)

The findings are consistent with Vanderbilt Occupational Health Clinic (2005) reports that the transmission of tuberculosis is by inhalation of droplet nuclei produced when a person with infectious pulmonary or laryngeal tuberculosis coughs, laughs, sneezes, sings, or talks in a shared breathing space without a mask and the other person not wearing an N95 respirator.

Another interviewee supported the above view by that it is culturally and religiously advised that people should cover their mouth when sneezing or coughing. However, many of the people do not practice it. Their failure to adhere to the cultural norms in this area influences the spread of the disease. The interviewee presented his points this way:

...Yes, covering of nose and mouth when sneezing or coughing is part of the teaching of Islam which is also the religion of most people living in this community, but we don't always practice it. (IDI/58years/Female/Community member/2015)

It was further revealed in the qualitative data that the nature of mining job influences the prevalence of TB in the area. It revealed that most of the miners work in the same mining pit which has little ventilation. As such if one of them is infected with TB, it is likely to be transmitted to many who work in the same pit. A respondents emphasized this point by saying:

As you can see, here we do work together in the same mining pits. ...If you go inside now, you will realise that there is no ventilation. ...yes...Some people usually smoke inside the pit. Some out of stress will even cough and expel saliva while inside the pit. The work is not hygienic but we have no option. (IDI/38years/Male/Community member/2015)

An interview with a respondent also revealed factors such as poverty, lack of formal education and treatment of health workers at hospitals as some of the issues influencing the spread of tuberculosis in the area. The interviewee put it this way:

Many of us in this community did not go to school. We find it difficult to differentiate tuberculosis disease from other disease. Since we can't differentiate, we cannot always be going to hospital. More so, we don't have money like that, and even hospital sometimes does select people who 'know book' to treat on time. (IDI/49years/Female/Community member/2015) 
Another respondent revealed that some traditional beliefs of the people influence the incidence of tuberculosis in the study area. For instance, the beliefs in roots and herbs, and the belief that the western medicines cannot cure some of the local diseases influence the spread of the disease. In the interviewee words:

...herbs and roots are better than hospitals. Hospitals cannot cure so many diseases that herbs and roots can cure. ...Okay, can hospital deliver someone from witches and wizard? It cannot. Herbs and roots are our traditions and culture, hospital is for 'oyibo', referring to Westerners... (IDI/57years/Male/Community members/2015)

An Interviewee further revealed that the beliefs that some diseases affect some people because of the modern kinds of food they eat influence the prevalence of the disease in the study area. An interviewee put it this way:

All these disease, including the one that is called TB are modern day's disease. They likewise accompanied modern day's foods and lifestyles... I was not aware of such disease until when I came into this community. (IDI/50years/Community member/ 2015)

Information from the KII conducted with one of the community health worker revealed that the nature of the peoples' jobs in the camp influenced the spread of the disease due to poor ventilation. In her views, she said:

Yes, the prevalence of TB is high in the community especially among the miners. ...it is the nature of their job and their personal behaviour that is causing it. For instance, most of them work in the same pit. While inside the pit, some of them smoke, and cough inside the pit. Others inhale it. Therefore, if any of them have a specific disease, the probability of many of them having the same disease is also high. (KII/50years/Male/Health worker/2015)

An official revealed that factors influencing the prevalence of tuberculosis in the area are the habit of smoking in the mining pits, having affair with prostitutes who may have the TB disease within the community, the lack of proper knowledge of how the disease is transmitted and how it could be prevented. The interviewee presented it this way:

...I have been mining here for the past 20 years. TB is a common disease in the camp. Our company has been doing everything possible to control it among our staff. Sometimes we do call on our health workers to come and educate the people on how to prevent TB infection. ...it is not the fault of the company that they have TB. Some got it from prostitute within the community during outing, and having affair with them. Some contract it by 
inhaling the smoke expel by an infected staff. ...as a matter of fact, we have even warned all the staff not to be smoking in the pit... (KII/45years/Male/Labour leader/2015)

From the foregoing, TB is prevalent in the study area and several factors both contribute to the prevalence of TB some of which are unknown or wrongly perceived by the respondents. The knowledge of TB goes a long way to determine peoples' ability to prevent its spread, seek for help when infected and adopt control measures. Respondents' explanation about the symptoms, causes and factors influencing its spread aligned with the explanatory model of Kleinman (1976) used in the study. The unequal access to health care due to unequal distribution of socio-cultural, environmental and economic conditions were determinants of the prevalence of TB thus corroborating views of the determinant model.

\section{Discussion}

The study has shown clearly that despite the fact that some respondents in the study area have experienced TB or witnessed people experience and received treatment at some point in time, there are still some misconception regarding the causes TB and how it can be prevented. For instance, over a quarter believed that the disease can result as a punishment from gods or goddess. Thus even when a large majority (95.0\%) have heard about the pandemic, and acquired their knowledge from enlightening sources like health workers $(30.7 \%)$, radio $(31.2 \%)$, a lot still needs to be done through these sources to enlighten respondents' further knowledge about the causes, symptoms and prevention of TB. This is because adequate knowledge about the disease is still lacking in an area where the populace is highly vulnerable to such a disease and corroborates the views of Omotowo et al. (2012) that knowledge of the aetiology and route of transmission of TB is still poor among people.

Results have also shown that while it is important to approach the prevention and control of TB bio-medically, there are several other social and cultural factors that can militate against the success of these measures, if they are not taking into consideration, such factors include the belief systems, social status, social relations etc. Furthermore, while $43.4 \%$ identified immunising against TB a s a way of preventing it, $22.5 \%$ believed that prayer can prevent it, while about $15 \%$ stated avoiding where there is crowd as preventive measures for TB. Over half of the respondents mentioned smokers and alcoholics as those vulnerable to the disease. This further supports the explanation of the social determinant model on the influence of social factors in the spread and control of diseases.

A major concern is evident in the confirmation of over half of the respondent that the incidence of $\mathrm{TB}$ is high and perceived to be highly contagious in the study area with several other risk factors such as HIV and 
poor immunity. With the experience of low knowledge and misconception, of the cause, prevention and control of the disease, it may be very difficult to achieve any reduction as recorded in other high-burdened communities. Perceiving TB a punishment from the gods can attract some form of stigmatization which may deter people from going for test, immunization and treatment to control the disease. A wholistic approach to correcting this impression may salvage the situation and re-direct the people to viewing the disease in a more objective manner.

\section{Conclusion and Recommendations}

The incidence of tuberculosis as a pandemic in a country that is categorized as high-burdened calls for urgent attention regarding its prevention and control. It is obvious that socio-cultural factors such as belief, age, gender and marital status of people influence the prevalence of tuberculosis in the study area. While there is increased knowledge of the incidence and awareness about the fact that the disease is preventable and curable, the knowledge about how these can be done, is quite lacking among the people. Socio-cultural factors such as religious beliefs, myths, self-medication, reliance on herbs and drugs, low education, communality, work environment and smoking habits greatly influence the prevalence of tuberculosis in the study area. There is therefore the need to look into these issues in attempting to proffer solutions to reduce the prevalence of tuberculosis. The paper therefore recommends that public health education targeting the mining staffs and community members, specifically on the prevention, symptoms, transmission, diagnosis, and treatment of tuberculosis should be organized in order to improve their knowledge in reducing the spread of TB disease in the study area. This could include more practical measures such as plays, adverts, village talks, jingles and the likes to re-orient and correct the misconceptions about the causal factors of TB. Furthermore, there is need for urgent intervention and control measure which should be adopted and implemented by government and non-governmental organisation to control the high prevalence of tuberculosis in the community. The process of diagnosing the incidence of tuberculosis should be made attractive in the study area to enable majority of the people for TB test exercise. This can be done by encouraging and motivating those who come for the test in the study. The test and sensitisation exercise should take into considerations social factors such as gender, religion and cultural background in attaining its goal. For instance, to get the attention of the Hausa women, their husbands and religious leaders should be fully informed and involved in the exercise especially because a significant proportion of the respondents in the study are from the Northern part of the country. Women health workers should therefore be included to have easy access to the Hausa women. 


\section{References}

Agho, K., Hall, J. and Ewald, B. (2014) Determinants of the Knowledge of and Attitude towards Tuberculosis in Nigeria. J Health Popul Nutr. 32(3): 520538.

Awoyemi, O., Ige, O., Onadeko, B. (2002) Pattern of Active Pulmonary Tuberculosis in Human Immunodeficiency Virus Seropositive Adult Patients in University College Hospital, Ibadan, Nigeria. Afr J Med Med Sci, 31: 25-31.

Colson, P., Franks, J., Sondengam, R., Hirsch-Moverman, Y. and El-Sadr, W. (2010) Tuberculosis Knowledge, Attitudes, and Beliefs in Foreign-born and US-born Patients with Latent Tuberculosis Infection. J Immigr Minor Health, 12: 859-66.

Comstock, G. (1986) Tuberculosis — a bridge to chronic disease epidemiology. Am. J. Epidemiol, 124: 1-16.

Demissie, M., Lindtjom, B., Berhane, Y. (2002). Patient and Health Service Delay in the Diagnosis of pulmonary tuberculosis in Ethiopia BMC Public Health, 2(1): 23.

Dim, C. and Dim, N. (2013) Trends of Tuberculosis Prevalence and Treatment Outcome in an Under-resourced Setting: The Case of Enugu State, South East Nigeria. Nigerian Medical Journal, 54(6): 392-7.

Gerrish, K., Ismail, M. and Naisby, A. (2010) Tackling TB Together: A Community Participatory Study of the Socio-cultural Factors Influencing an Understanding of TB within the Somali Community in Sheffield. Shefield Hallam University, Centre for Health and Social Care Research, Collegiate Crescent, Sheffield.

Jose, A. (2003) A Tuberculosis Guide for Specialist Physicians. International Union Against Tuberculosis and Lung Disease, Paris, France.

Keers, R. (1978) Pulmonary Tuberculosis: a Journey down the Centuries. London, Bailliere Tindall.

Kleinman, A. (1976) Culture, Illness and Care: Clinical Lessons from Anthropologic an Cross-cultural Research. Annals of Internal Medicine, 88: 251-258.

Koay, T. (2004) Knowledge and Attitudes Toward Tuberculosis among the People living in Kudat District, Sabah. Med J Malaysia; 59: 502-11.

Lienhardt, C., Fielding, K., Sillah, J., Bah, B., Gustafson, P., Warndorff, D. (2005) Investigation of the Risk Factors for Tuberculosis: A Case-control Study in Three countries in West Africa. Int J Epidemiol, 34: 914-23.

Lienhardt, C. (2001) From Exposure to Disease: The Role of Environmental Factors in Susceptibility to and Development of Tuberculosis. Epidemiol Rev, 23: 288-301.

Mohamed, A., Yousif, M., Ottoa, P. and Boyoumi, A. (2007) Knowledge of Tuberculosis: A Survey Among Tuberculosis Patients in Omdurman, Sudan. Sudanese Journal of Public Health, 2: 21-28. 
Mutinda, A., Kabiru, E. and Mwaniki, K. (2014) Health seeking behavior, practices of TB and access to health care among TB patients in Machakos County, Kenya. A Cross-Sectional Study. Journal of Biology, Agriculture and Healthcare. 4(14).

Okuonghae, D. and Omosigho, S. (2010) Determinants of TB Case Detection in Nigeria: A Survey. Glob J Health Sci, 2: 123-8.

Omotowo, B, Ekwueme, O., Aghaji, M. (2012) Tuberculosis Control Mechanisms and Contact Tracing: Knowledge and Practice among TB Patients at Dots Centers in Southeast Nigeria. 1:451. doi:10.4172/Scientificreports.451.

Pott, P. (1937) Remarks on that kind of palsy of the lower limbs, which is frequently found to accompany a curvature of the spine, and is supposed to be caused by it, together with its method of cure. Med. Classics, 1: 281297, 1936-1937.

Reichman, L. and Hershfield, E. [editors] (1993) Tuberculosis. A Comprehensive International Approach, New York: Marcel Dekker.

Rieder, H., Cauthen, G., Comstock, G. and Snider, D. (1989) Epidemiology of tuberculosis in the United States. Epidemiol. Rev., 11: 79-98.

Sagbakken, M. (2010) Experiences of Being Diagnosed with Tuberculosis among Immigrants in Norway - Factors Associated with Diagnostic Delay: A Qualitative Study. Journal of Public Health, 38(3): 283-90.

Small, P., Schecter, G., Goodman, P., Sande, M., Chaisson, R. and Hopewell, P. (1991) Treatment of tuberculosis in patients with advanced human immunodeficiency virus infection. New England J. Med., 324: 289-294.

U.S. Department OF Health and Human Services (2008) Tuberculosis: Getting Healthy, Staying Healthy. National Institutes of Health. National Institute of Allergy and Infectious Diseases. NIH Publication. Available at www.niaid.nih.gov

United States Embassy in Nigeria (2012) Nigeria Tuberculosis Fact Sheet. Economic Section, United States Embassy in Nigeria Plot 1075, Diplomatic Drive Central Area Abuja, FCT, Nigeria.

Vanderbilt Occupational Health Clinic (2005) Exposure to Tuberculosis. Office of Risk Management. Available at www.vanderbillt.edu/ohctb.

Wandwalo, E. and Morkve, O. (2000) Knowledge of Disease and Treatment among Tuberculosis Patients in Mwanza, Tanzania. Int J Tuberc Lung Dis 4: 1041-1046.

Watts, G. and Lifeso M. (1996) Current Concepts Review: Tuberculosis of Bones and Joints. The Journal of Bone and Joint Surgery, Incorporated. 78-A(2).

Weiss, M., Doongaji, D., Siddhartha, S., Wypic, D., Pathare, S., Bhatawdekar, M., Bhave, A., Sheth, A. and Fernandes, R. (1992) The Explanatory Model Interview Catelogue (EMIC): Contribution to Cross-cultural Research Methods from a Study of Leprosy and Mental Health. British Journal of Psychiatry, 160: 819-930. 
WHO (2010) Global Tuberculosis control 2010 Nov.2010. NLM classification WF 300. Avenue Appia 1211 Geneva 27 Switzerland.

WHO (2014) Global Tuberculosis report 2012.WHO report. Geneva Switzerland.

WHO.2009. Stop TB Partnership facts 2009. http://www.who.int/media centre/ fact sheets/fs 104/en accessed 31.7.2014.

Word Bank. 2007. Tuberculosis.http://web.worldbank.org. Accessed 8/1/2014. 